\title{
Crystal Growth and Physico-Chemical Characterization of Semi-Organic [C4H12N2] ZnCl4. H2O Single Crystal for Laser Applications
}

Karuppasamy Pichan ( $\sim$ karuppasamyp75@gmail.com )

Sri Sivasubramaniya Nadar College of Engineeing https://orcid.org/0000-0002-0633-0428

\section{T. Kamalesh}

Sri Sivasubramaniya Nadar College of Engineering

\section{Senthilpandian}

Sri Sivasubramaniya Nadar College of Engineering

P. Ramasamy

Sri Sivasubramaniya Nadar College of Engineering

\section{Research Article}

Keywords: Single crystal, X-ray diffraction (XRD), Optical transmittance, Mechanical, Dielectric, Z-scan technique

Posted Date: March 12th, 2021

DOl: https://doi.org/10.21203/rs.3.rs-281095/v1

License: (9) This work is licensed under a Creative Commons Attribution 4.0 International License. Read Full License 


\title{
Crystal Growth and Physico-Chemical Characterization of Semi- Organic $\left[\mathrm{C}_{4} \mathrm{H}_{12} \mathrm{~N}_{2}\right] \mathrm{ZnCl}_{4} . \mathrm{H}_{2} \mathrm{O}$ Single Crystal for Laser Applications
}

\author{
P. Karuppasamy*, T. Kamalesh, M. Senthil Pandian, P. Ramasamy
}

SSN Research Centre, Sri Sivasubramaniya Nadar College of Engineering, Chennai-603110,

Tamil Nadu, India 


\begin{abstract}
:
Optical high quality semi-organic piperazinium tetrachlorozincate monohydrate, $\left[\mathrm{C}_{4} \mathrm{H}_{12} \mathrm{~N}_{2}\right] \mathrm{ZnCl}_{4} . \mathrm{H}_{2} \mathrm{O}$ (PTCZ) single crystals were grown by conventional solution method. The structure of grown crystal was confirmed by the single crystal X-ray diffraction (SXRD) analysis. The material phase purities and its various (hkl) planes have been confirmed by the powder X-ray diffraction (PXRD) analysis at room temperature. The different functional groups were confirmed by the Fourier-transform infrared (FTIR) spectroscopy. The optical quality of the PTCZ single crystal and band gap energy have been identified by the UV-Vis NIR spectral analysis and also calculated refractive index of the material. The thermal stability of the PTCZ single crystal was investigated by TG-DTA. The hardness related properties were analyzed by microhardness tester. The dielectric properties have been measured on the grown single crystal and the electronic polarizability value has been calculated with various theoretical approach. The etching process was carried out on the grown crystal to finding the dislocation density. The crystal atomic perfection has been investigated by the high resolution X-ray diffraction (HRXRD) or Rocking curve (RC) analysis. The Z-scan measurement has been carried out to finding third-order optical susceptibility $\left(\chi^{(3)}\right)$ of the grown single crystal using solid state laser $(640 \mathrm{~nm})$.
\end{abstract}

Keyword: Single crystal; X-ray diffraction (XRD); Optical transmittance; Mechanical; Dielectric; Z-scan technique.

\title{
1. Introduction:
}

In recent years, optoelectronics and photonics have created more attention on nonlinear optical (NLO) materials. It is a major role for frontier of science and technology in the emerging 
field of photonics, which involves the many applications. However, in the form single crystals are most important for wide range of optoelectronic applications such as laser harmonic generations (SHG, THG, 4HG), sum or difference frequency generation (SFG, DFG) and etc. [1-2]. The development of photonics and optoelectronic technologies rely heavily on the growth of NLO materials with quick responses. The new materials must possess high nonlinear response, shorter cut-off wavelength, higher transparency window, high laser power threshold and good physicchemical stability. However, the organic materials shows prominent properties due to their fast nonlinear response, more possibility of synthetic flexibility and high laser power threshold limit [3]. Even though, the organic materials may suffer from many problems such as volatility, low thermal stability, poor mechanical stability and etc. Whereas, inorganic materials possess excellent mechanical and optical properties but have low effect of nonlinearities. However, these difficulty are overcome by introducing a new phase of semi-organic single crystal and it can be grow bulk form with higher quality. Because of it reflecting effects from both the organic and inorganic aspect and remarkably excellent characteristics.

Piperazine and its substituted materils are useful for pharmacophores that can be found in many drugs. The derivative of piperazine is found in biologically active components across a number of various therapeutic areas such as antifungal, antibacterial, antimalarial and etc. [4]. In this view, research has more attracted and considerable attention in the development of good NLO materils. Piperazine is a saturated heterocyclic hydrocarbon (cyclic diamine) with the two nitrogen atoms capable of forming hydrogen bond network. It is an achiral organic weak base with the space group $\mathrm{P} 2{ }_{1} / \mathrm{n}$ [5]. It contained a cycloaliphatic secondary amine with two protonated amine $(\mathrm{NH})$ groups in a six membered saturated ring [6]. It has a strong hyderogen bond acceptor in nature due to enhanceing both second and third order nonlinear optical properties. For example, the piperzine 
molecule is bonded to the halogenate metals and these kinds of bonds have been also observed in the isotypic crystal structures [7-8]. In the present investigation, the optically high quality semiorganic single crystals of piperazinium tetrachlorozincate monohydrate (PTCZ) have been grwon by the solution method. The grown crystals were subjected to various characterizations.

\section{Experimental}

\subsection{Material synthesis, crystal growth and morphology}

The analytical grade of piperazine $\left(\mathrm{C}_{4} \mathrm{H}_{10} \mathrm{~N}_{2}\right)$, zinc chloride $\left(\mathrm{ZnCl}_{2}\right)$ and hydrochloride acid $(\mathrm{HCl})$ were taken in the ratio of $1: 1: 2$ in a water solvent to syntheses of $\left[\mathrm{C}_{4} \mathrm{H}_{12} \mathrm{~N}_{2}\right] \mathrm{ZnCl}_{4} \cdot \mathrm{H}_{2} \mathrm{O}$ (PTCZ) materials. The same materials have been taken in glass container based on the solubility data. The clear solution was obtained by mechanical stirred for few hours at room temperature. The prepared solution was filtered into glass crystallizer using a Whatman filter paper. The filtered solution poured into the glass petri-dish and make a controlled evaporation of the solvent at room temperature. The reaction scheme of PTCZ is given below. The synthesized materials have been purified by the repeated crystallization process. The good quality PTCZ single crystals with dimension of $3 \times 2 \times 2 \mathrm{~mm}^{3}$ have been obtained after few weeks. The grown PTCZ single crystals are shown in Fig. 1. The morphology of the gown crystal was indexed by WinXMorph software and it is shown in Fig. 2.

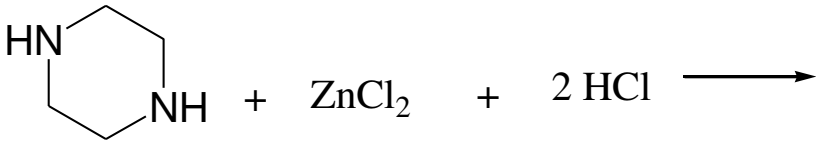

Piperazine Zinc chloride Hydrochloric acid

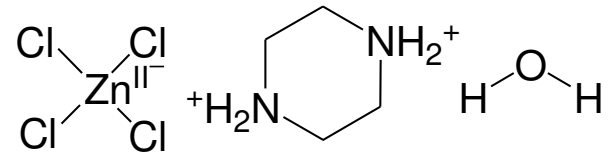

Piperazinium tetrachlorozincate monohydrate

\subsection{Solubility measurement}


Solubility of the material is essential which to be used in solution crystal growth process. This measurement has been carried out with different temperature range $\left(35^{\circ} \mathrm{C}\right.$ to $\left.60{ }^{\circ} \mathrm{C}\right)$ using water solvent. Initially, the water bath was maintained at $35^{\circ} \mathrm{C}$ with control accuracy of $\pm 0.01{ }^{\circ} \mathrm{C}$. $100 \mathrm{~mL}$ of double distilled water was taken in an air tight conical flask and it continuously stirred using immersible magnetic stirrer. The recrystallized salts have been dry out for few days before the started this measurement. After that, the same materials was grained continuously by the mortar up to get very fine powder. Further, the powdered materials was packed in a zip-lock cover. The initial weight was measured by the precision weight balance machine and it represent ' $\mathrm{W}_{0}$ '. The quantity of ' $\mathrm{W}_{0}$ ' was slowly added into the container. At particular stage, solute particles could not dissolved, however, the solution was attained the saturation for that particular temperature. Now the reaming salt weight was noted and it represent $\mathrm{W}_{1}$. It was repeated for different temperature (weight) such as $40{ }^{\circ} \mathrm{C}\left(\mathrm{W}_{2}\right), 45^{\circ} \mathrm{C}\left(\mathrm{W}_{3}\right), 50{ }^{\circ} \mathrm{C}\left(\mathrm{W}_{4}\right), 55^{\circ} \mathrm{C}\left(\mathrm{W}_{5}\right)$ and $60^{\circ} \mathrm{C}\left(\mathrm{W}_{6}\right)$ and etc. The solubility of the materials has been calculated for $100 \mathrm{ml}$ of solvent using equation as given below. The solubility of PTCZ single crystal is shown in Fig. 3.

$$
\text { Solubility }(\mathrm{g} / \mathrm{ml})=\frac{\left(W_{0}-W_{x}\right)}{100 m l} \text {; here, } x=1,2,3,4,5,6 \text { andetc. }
$$

\section{Results and discussion}

\subsection{X-ray diffraction (XRD) analysis}

The grown PTCZ crystal was subjected to SXRD at room temperature using Enraf Nonius CAD4-F diffractometer with $\mathrm{MoK}_{\alpha}$ monochromatic $(\lambda=0.710 \AA)$ radiation. From the observation, the PTCZ crystal is monoclinic with dimension of $a=6.58 \AA, b=12.80 \AA, c=14.04 \AA$ and $\beta=$ $92.73^{\circ}$, which is in well matched with the reported value [9] and the details are given in Table. 1. The PTCZ molecular structure and packing diagram are shown in Fig. 4 and Fig. 5 respectively. 
The PXRD measurement has been carried out using PANalytical X'Pert Pro XRD with the $\mathrm{CuK}_{\alpha}$ (1.5406 $\AA$ ), step size $(2 \theta)$ of $0.020^{\circ}$ and scanning time for 5 minute at room temperature in order to finding the material phase and various (hkl) planes. It was performed on the $2 \theta$ scans from $5^{\circ}$ to $80^{\circ}$. The PXRD spectrum of PTCZ is shown in Fig. 6. From the spectrum, the well resolved intense peaks were observed and hence it indicates that the grown crystal is good in structural/ crystalline perfections.

\subsection{FTIR Spectral Studies}

Vibrational spectroscopy is an important tools to analysis the various functional groups in the given structure. It gives the broad information about the chemical bonding and molecular related information. The FTIR spectrum of PTCZ crystal (Fig. 7) was recorded using ATR mode in the wavenumber range between $500 \mathrm{~cm}^{-1}$ to $4000 \mathrm{~cm}^{-1}$. This measurement was carried out by the Perkin-Elmer spectrometer. From the spectrum, the peak at $3539 \mathrm{~cm}^{-1}$ is indicates that the strong $\mathrm{N}-\mathrm{H}$ stretching vibration in the piperazine moiety. The peaks at $3019 \mathrm{~cm}^{-1}$ and $2782 \mathrm{~cm}^{-1}$ indicate that the $\mathrm{C}-\mathrm{H}$ stretching in a benzene ring. The $1635 \mathrm{~cm}^{-1}$ and $1551 \mathrm{~cm}^{-1}$ are assigned to the $\mathrm{NH}_{2}{ }^{+}$deformation in the piperazinium moiety [10]. The $1441 \mathrm{~cm}^{-1}$ is belongs to $\mathrm{CH}_{2}$ stretching in the piperazinium ring wall [11]. The $1305 \mathrm{~cm}^{-1}$ and $1187 \mathrm{~cm}^{-1}$ are indicates the symmetric mode and in-plane bending vibration of C-H group. The $\mathrm{N}-\mathrm{H}$ bending mode was confirmed at $911 \mathrm{~cm}^{-1}$. The C-N deformation was found at $860 \mathrm{~cm}^{-1}$. The peak at $557 \mathrm{~cm}^{-1}$ is indicates due to the presence of C-C-N deformation [12].

\subsection{UV-Vis NIR spectral measurement}


The optical high quality single crystalline materials are essential for optoelectronic device applications [13-14]. The optical transmittance of PTCZ single crystal was recorded using spectrophotometer in the ranges from $200 \mathrm{~nm}$ to $1100 \mathrm{~nm}$ (model: Perkin-Elmer Lambda-35). Resultant, the grown PTCZ single crystal has high transparency with wide window as shown in Fig. 8 (a). The high transparent in the entire visible region is a desirous property for the materials to be used in NLO applications. Also the cut-off wavelength is $200 \mathrm{~nm}$ (approximately $180 \mathrm{~nm}$ ). Hence PTCZ may useful for frequency conversion applications. The absorption of electromagnetic radiation gives information about the structure of the molecule. Therefore, linear absorption coefficient $(\alpha)$ of the given material can be calculated different wavelength in the region of 200 $1100 \mathrm{~nm}$ [15-16]. In the transmittance spectrum, the material thickness is the major role for determining ' $\alpha$ ' and it defined by the following relation [16].

$$
\alpha=\frac{2.3026}{t} \log _{10}\left(\frac{100}{T}\right)
$$

where ' $t$ ' is the sample width $(1.2 \mathrm{~mm})$ and ' $T$ ' is transmittance $(\%)$. The optical band gap energy $\left(E_{g}\right)$ can be estimated using the following Tauc plot relation:

$$
(\alpha h v)=A\left(h v-E_{g}\right)^{\frac{1}{2}}
$$

where ' $A$ ' is the material constant, ' $v$ ' is the frequency of incident ray and $h$ is the Planck's constant. The Tauc plot has been carried out by putting a graph between $(\alpha h v)^{2}$ and photon energy (hv). From this graph, the $E_{g}$ can be estimated by extrapolation of linear curve to meet the value of $\alpha=0$ on the X-axis, which is shown in Fig. 8 (b). The $E_{g}$ of grown PTCZ single crystal was found to be around $6.2 \mathrm{eV}$. Further, other optical parameters such as reflectance $(R)$ and linear refractive index $\left(n_{0}\right)$ with different wavelength can be calculated theoretically using following expressions $[17,18]$. 


$$
\begin{gathered}
R=\frac{\exp (-\alpha t) \pm\left[\exp (-\alpha t) T-\exp (-3 \alpha t) T+\exp (-2 \alpha t) T^{2}\right]^{1 / 2}}{\exp (-\alpha t)+\exp (-2 \alpha t) T} \\
n_{0}=\frac{-(R+1) \pm 2[R]^{1 / 2}}{(R-1)}
\end{gathered}
$$

The reflectance versus wavelength of the PTCZ single crystal is shown in Fig. 9 (a). The obtained reflectance data are substituted to the refractive index equation. The value of ' $n_{0}$ ' versus wavelength is shown in Fig. 9 (b). The $n_{0}$ of the PTCZ single crystal was found to be 2.8 at 640 nm. It can be used in the Z-scan experiment part to calculated the third order nonlinear optical susceptibility $\left(\chi^{(3)}\right)$ of PTCZ crystal.

\subsection{Thermal analysis}

The thermal behavior of the PTCZ single crystal have been carried out using Perkin- Elmer Diamond TG-DTA analyzer. This process was taken under nitrogen at a heating rate of $10^{\circ} \mathrm{C} / \mathrm{min}$. The TG-DTA curve of PTCZ single crystal is shown in Fig. 10. From this curve, the peaks at $75^{\circ} \mathrm{C}$ and $95^{\circ} \mathrm{C}$ due to liberation of adsorbed water molecules and another loss at $115^{\circ} \mathrm{C}$ is due to removing of water molecules from the PTCZ single crystal. Further, the temperature was increases, there is no remarkable weight loss observed between $115^{\circ} \mathrm{C}$ and $290^{\circ} \mathrm{C}$. In the PTCZ system, the piperazine molecules strongly bounded to the chlorine $(\mathrm{Cl})$ atoms coordinated to a $\mathrm{zinc}(\mathrm{Zn})$, this is reason for increasing thermal stability of the system. The endothermic peak started from $290{ }^{\circ} \mathrm{C}$ to $355^{\circ} \mathrm{C}$ and $360{ }^{\circ} \mathrm{C}$ is indicates that the removing of $\mathrm{Zn}$ and $\mathrm{Cl}$ atoms from the compound and its losses upto $66 \%$. When the temperature reached at $465^{\circ} \mathrm{C}$, the $10 \%$ weight loss observed, which is indicates that the removing of some volatile substance. Remaining $10 \%$ is may indicates the residual carbons. Therefore the PTCZ single crystal is stable upto $70^{\circ} \mathrm{C}$.

\subsection{Microhardness Studies}


Vickers microhardness is a most common reliable technique for analysis the mechanical behavior of the given materials. Normally, hardness nature of the material is related to the structure of the material which made and its types of bonds. Initially, crack free and very smooth as-grown surfaces single crystal has been selected. The selected single crystal was mounted on the sample holder without deviation/tilting. This experiment has been carried out using a Shimadzu HMVG21 attached with a diamond indentor. The different loads $(P)$ from $5 \mathrm{~g}$ to $100 \mathrm{~g}$ were applied on the test sample surface at various places. The time of each indentation was kept 5 seconds for entire experiment. The indentation patterns each loads are shown in Fig. 11. The two diagonal length of each indentation patterns have been measured by supporting an optical microscope and its average of diagonal length was taken for this calculation. Vickers hardness number $\left(H_{v}\right)$ has been calculated using the following standard relation [19].

$$
H_{v}=\frac{1.8544 P}{d^{2}}\left(\mathrm{Kg} / \mathrm{mm}^{2}\right)
$$

The $H_{v}$ versus applied load (P) for PTCZ crystal is illustrated in Fig. 12 (a). From the graph, the $H_{v}$ is increases with increasing applied loads $(\mathrm{P})$, which is indicates as reverse indentation size effect (RISE) [20]. After $50 \mathrm{~g}$ of load, the hardness number is increasing slightly and towards straight line. It represent that the grown crystal is more possibility to get damage at above $100 \mathrm{~g}$ of applied load. The hardness coefficient ( $n$ ) value of the grown PTCZ single crystal was calculated by using Meyer's relation [21] and is shown in Fig. 12 (b).

$$
P=A d^{n}
$$

According to Onitsch condition, $n$ is 1 to 1.6 for hard and above 1.6 for soft materials category [22]. From this observation, the values of ' $n$ ' was found to be 2.23 and hence the grown PTCZ confirm that the soft material category. Other mechanical parameters such as fracture 
toughness $\left(K_{c}\right)$, brittleness $(B i)$, yield strength $\left(\sigma_{y}\right)$ and elastic stiffness constant $\left(C_{11}\right)$ were calculated using following standard relations.

\begin{tabular}{|l|l|l|l|}
\hline Fracture toughness & Brittleness & Yield strength $\left(\sigma_{y}\right)$ & Elastic stiffness \\
\hline$\left.K_{c}\right)$ & index $\left(B_{i}\right)$ & constant $\left(C_{11}\right)$ \\
\hline$K_{c}=\frac{P}{\beta_{0} l^{3 / 2}} ;$ if $l \geq \frac{d}{2}$ & $B_{i}=\frac{H_{v}}{K_{c}}$ & $\sigma_{y}=\frac{H_{v}}{2.9}[1-(n-2)]\left(\frac{12.5(n-2)}{1-(n-2)}\right)^{n-2}$ & $C_{11}=\left(H_{v}\right)^{7 / 4}$ \\
\end{tabular}

The mechanism of fracture is developed in the materials by in the indentation. It gives an equilibrium relation for a well-developed crack increases under the loading conditions [23]. Fracture toughness $\left(K_{c}\right)$ is closely related to hardness or strength of a material. The strength is an important for ability to resist deformation under the given applied load [24]. The fracture toughness $\left(K_{c}\right)$ versus load $(P)$ of PTCZ single crystal is shown in Fig. 13 (a). A graph plotting between $P$ and $l^{3 / 2}$, which gives the average value of the fracture toughness of the grown single crystal. It was found to be $0.0988 \mathrm{~g} /(\mu \mathrm{m})^{3 / 2}$ for the grown PTCZ single crystal.

The brittleness $(\mathrm{Bi})$ is an important mechanical parameter for material researchers [23]. It explains the deformation limit of the given materials. The inducing fracture is developed on the test material but without any appreciable deformation. The machinability of a material can be measured accordance with the brittleness index. Materials with good machinability require minimum power to cut, can be cut quickly, easily get good finish and do not wear the tooling much. The value of brittleness index $(B i)$ versus applied load $(P)$ is shown in Fig. 13 (b). It is decreases with increasing loads.

The yield strength $\left(\sigma_{y}\right)$ of the PTCZ can be calculated by using a Meyer's index $(n)$ number and it satisfied condition of $(2<n<3)$ [25]. A graph plotted yield strength $\left(\sigma_{y}\right)$ versus applied load 
$(P)$ is shown in Fig. 13 (c). The yield strength is increases with increasing applied load up to $50 \mathrm{~g}$ and then sudden falling down is due to overload on the test material.

The elastic stiffness constant $\left(C_{11}\right)$ can be calculated using Wooster's empirical formula [26]. It gives a more information about the bonding strength of the test material. It is the important parameter for materials researchers, because, the bond strength is a major role for desiring many mechanical properties. Fig. 13 (d) shows the stiffness constant $\left(\mathrm{C}_{11}\right)$ versus applied loads. The calculated mechanical parameters such as $H_{v}, \sigma_{y}, C_{11}, K_{c}$ and $B_{i}$ of PTCZ single crystal for different loads are given in Table 2.

\subsection{Dielectric studies}

The electrical behavior (dielectric constant and loss) of PTCZ single crystal has been investigated by the dielectric measurement using PSM LCR meter. The sample thickness of $2 \mathrm{~mm}$ was used. The good electrical contact layer on the both surfaces of the sample will be made by applying conductive paste (silver) without any overlapping. Further, the same sample was placed in a hot plate for few minutes at $40{ }^{\circ} \mathrm{C}$. This process may be useful for avoiding/reducing air gaps and also avoid external polarization by the air molecules [27]. The prepared sample was kept in a sample holder (made of copper) to form like a parallel plate capacitor. Before starting the experiment, we have verified the electrical connection between two electrodes and sample surface by using the multi-meter. The material capacitance values and dissipation factors with function of frequency from $1 \mathrm{~Hz}$ to $5 \mathrm{MHz}$ at room temperature have been measured. From these values, we can be calculated the dielectric constant of the materials by the following equation [28]. The dissipation factor is directly consider as a dielectric loss $(\tan \delta)$.

$$
\varepsilon^{\prime}=\frac{C_{p} d}{\varepsilon_{0} A}
$$


where, $A$ is the sample area, $d$ is the thickness and $\varepsilon_{0}$ is the permittivity of free space $\left(8.854 \times 10^{-}\right.$ $\left.{ }^{12} \mathrm{~F} / \mathrm{m}\right)$. Dielectric constant $\left(\varepsilon^{\prime}\right)$ and dielectric loss (tan $\delta$ ) of the grown PTCZ single crystal were studied as a function frequencies and it is shown in Fig. 14 (a) and (b) respectively. From the figures, it is observed that the grown crystal has higher dielectric constant in the lower frequency region as well less dielectric loss. These are decreases with an increasing the frequency ranges. During the measurement, there are many polarization process contributes in the dielectric media such as electronic, ionic, orientation and space charge. These all the polarizations are active in lower frequencies region. But, these contribution are decreases when increasing the frequency. However, at higher frequency the dielectric constant becomes less. The heat energy is not avoidable in the dielectric materials, it is a power dissipation factor. It is directly proportional to the dielectric loss (tan $\delta$ ) [29]. The lower dielectric loss is represents that the grown crystal become a less defects.

The polarizability $(\alpha)$ is an important parameter for the desired the efficiency of nonlinear optical materials. The electronic polarizability $(\alpha)$ can be calculated theoretically in various ways $[27,10]$. The dielectric constant $\left(\varepsilon^{\prime}\right)$ is based on the free electrons present in the given materials structure. Theoretically, the electronic polarizability $(\alpha)$ through Penn gap analyses for PTCZ single crystal can be calculated using the following relation: [29]

$$
\alpha=\left[\frac{\left(\eta \omega_{p}\right)^{2} S_{0}}{\left(\eta \omega_{p}\right)^{2} S_{0}+3 E_{p}{ }^{2}}\right] \times \frac{M}{\rho} \times 0.396 \times 10^{-24} \mathrm{~cm}^{3}
$$

Here, the plasma $\left(\hbar \omega_{P}\right)$, Penn gap $\left(E_{P}\right)$ and Fermi $\left(E_{F}\right)$ energies have to be calculated. The relation of plasma energy $\left(\hbar \omega_{P}\right)$ as given below: 


$$
\eta \omega_{p}=28.8\left(\frac{Z^{\prime} \times \rho}{M}\right)^{\frac{1}{2}}
$$

where, ' $\rho$ ' is the density of PTCZ molecule $\left(1.8 \mathrm{~g} / \mathrm{cm}^{3}\right)$, ' $M$ ' molecular weight $(313.38 \mathrm{~g} / \mathrm{mol})$ and the total number of valence electrons of PTCZ crystal is $Z^{\prime}=\left[\left(4 \times Z^{\prime}\right)+\left(14 \times Z^{\prime}{ }_{\mathrm{H}}\right)+\left(2 \times Z^{\prime}\right)+\right.$ $\left.\left(1 \times \mathrm{Z}_{\mathrm{O}}^{\prime}\right)+\left(1 \times \mathrm{Z}_{\mathrm{Zn}}^{\prime}\right)+\left(4 \times \mathrm{Z}_{\mathrm{Cl}}^{\prime}\right)\right]=48$. It can be calculated by substituting for each atom of $\mathrm{C}, \mathrm{H}, \mathrm{N}$, $\mathrm{O}, \mathrm{Zn}$ and $\mathrm{Cl}$ as the corresponding valence electrons such as 4, 1, 5, 6, 2 and 1 respectively. According to the Penn model [30], the Penn gap $\left(E_{P}\right)$ and Fermi energy $\left(E_{F}\right)$ [31] for PTCZ are calculated using the following two relations:

$$
\begin{aligned}
& E_{P}=\frac{\eta \omega_{p}}{\left(\varepsilon^{\prime}-1\right)^{\frac{1}{2}}} \\
& E_{F}=0.2948\left(\eta \omega_{p}\right)^{\frac{4}{3}}
\end{aligned}
$$

where, $\varepsilon^{\prime}$ is the dielectric constant of the material at $1 \mathrm{MHz}$ and it was found to be 140 . Further, $S_{0}$ is a constant for a particular material which is given by

$$
S_{0}=1-\left[\frac{E_{p}}{4 E_{F}}\right]+\frac{1}{3}\left[\frac{E_{p}}{4 E_{F}}\right]^{2}
$$

According to Clausius-Mossotti relation [28], the electronic polarizability $(\alpha)$ is given by:

$$
\alpha=\frac{3 M}{4 \pi N_{A} \rho}\left(\frac{\varepsilon^{\prime}-1}{\varepsilon^{\prime}+2}\right) \mathrm{cm}^{3}
$$

Maxwell relation is give the statement for high-frequency electric field visible light stated that the $\varepsilon^{\prime}=n_{0}{ }^{2}$. The linear electronic polarizability $(\alpha)$ and refractive index $\left(n_{0}\right)$ of material are 
related each other and it described by the Lorentz- Lorenz equation [32]. Based on the conditions, the above equation can be modified and it is given by

$$
\alpha=\frac{3 M}{4 \pi N_{A} \rho}\left(\frac{n_{0}{ }^{2}-1}{n_{0}{ }^{2}+2}\right) \mathrm{cm}^{3}
$$

The optical band gap is also helps to finding the electronic polarizability $(\alpha)$ of the material, which is given by

$$
\alpha=\left[1-\frac{\sqrt{E_{g}}}{4.06}\right] \times \frac{M}{\rho} \times 0.396 \times 10^{-24} \mathrm{~cm}^{3}
$$

where $E_{g}$ is the optical band gap energy $(\mathrm{eV})$ of the PTCZ single crystal. The obtained electronic polarizability for the PTCZ crystal are higher than the KDP crystals [33]. The electronic polarizability $(\alpha)$ of grown PTCZ crystal was obtained by various theoretical ways and these values are in good agreement with each other. The obtained results are listed in Table. 3.

\subsection{Surface Etching analysis}

The NLO efficiency is mainly depends on the grown crystal quality, because of the imperfection or impurities may accumulate to develop the dislocations in the crystal during the growth process (any growth methods). Formation of defects/ dislocations are more possible get in the distortion of the laser beam, when the material to be processed [34]. There are many factors involving crystal growth process to affecting the quality of the growing single crystals: impurities, uncontrollable growth, physical and thermal distortion and etc. Resultant the grown crystal is contains many defects such as hillocks, twins, voids and etc. However, investigation dislocation is very crucial role for materials to be used in optoelectronic applications. The visually defect free single crystal was selected for this process. The etching process has been carried out on the grown 
PTCZ single crystal using water as an etchant at room temperature. First, the prepared PTCZ single crystal was dipped in the Millipore water for 2 seconds and it was cleaned properly by tissue paper. Second, the same surface was examined by an optical microscope with suitable magnification. Here, etch pits are not formed and it could not be seen. The same process was repeated for 5 seconds, the elongated linear etch pits were observed on the surface. The pure and etched surface of the PTCZ single crystal are shown in Fig. 15. The etch pits density (EPD) of PTCZ single crystal was analyzed manually using optical microscope and it can be calculated by number of etch pits followed by given area. The calculated EPD of PTCZ single crystal was found to be $3.2 \times 10^{3}$ $\mathrm{cm}^{-2}$.

\subsection{HRXRD}

Crystalline perfection is the major role for their optical device performance, which depends on the growth techniques and environments [35-36]. The crystalline atomic perfection of the grown single can be investigated by the high resolution X-ray diffraction (HRXRD). The grown bulk size single crystal was placed in the PXRD holder and get the diffraction patterns for PTCZ crystal. The HRXRD has been done on the selected (hkl) plane, at $2 \theta=17.5^{\circ}\left(\omega=8.75^{\circ}\right)$. The monochromatic $\left(\mathrm{CuK} \alpha_{1}\right) \mathrm{X}$-ray beam has been obtained from four bound silicon (220) bouncer. Further that beam has been collimated by controlling the slits (horizontal/vertical: $0.5 \mathrm{~mm} / 0.25$ $\mathrm{mm}$ ). The obtained fine beam is used for this analysis. The preliminary scanning of fine calibration offset such as $\omega, 2 \theta, \varphi, \chi$ and $\mathrm{Z}$ are analyzed with respect to the selected (hkl) plane and it is set to be zero position. The rocking curve (RC) was recorded by the $\omega$-scan where the detector was kept at the Bragg angle position with horizontal slit opening at front of the point detector, without alignment of the sample or any other position. A HRXRD diffraction curve or RC-spectrum of the PTCZ crystal is shown in Fig. 16. The full width at half maximum (FWHM) of the RC was found 
to be 17.06 arc sec, it indicating that the crystalline perfection of the grown PTCZ single crystal was good. This low FWHM is represent that there is no any structural distortions and low/very low angle grain boundaries present in the grown PTCZ single crystal. The curve is looks like a quiet sharp with a good vertically axis-symmetry with respect to the exact Bragg position (taken as zero). This axis-symmetric is confirms that the grown crystal has very less or no vacancy and interstitial defects in its atomic substitutional positions [36]. However, such type of single crystals are more useful for high performance nonlinear optical (NLO) devices.

\subsection{Z-scan measurement}

The Z-scan technique is an important tools to determine the third-order NLO properties of the crystalline materials. The grown PTCZ single crystal has been subjected to the Z-scan measurement to determine the nonlinear refractive index $\left(n_{2}\right)$ and absorption co-efficient $(\beta)$ [3738]. The solid state laser $(20 \mathrm{~mW})$ of wavelength at $640 \mathrm{~nm}$ was used as a source. The polarized Gaussian beam $\left(\mathrm{TEM}_{00}\right)$ was focused by a convex lens $(30 \mathrm{~mm})$. The thickness of the sample (L) is $0.6 \mathrm{~mm}$ and it was fixed vertically on a sample holder $\left(90^{\circ}\right.$ respect to beam direction). The sample was moved along the Z-axis front and back with the desired steps by the programmable stepper motor system, which was connected to the computer. During the each moment of sample, the transmitted intensity was collected by a photo detector. The schematic diagram of Z-scan system is shown in Fig. 17. Normally, in the closed aperture experiment, the received intensity depends on the radius of the aperture $(2 \mathrm{~mm})$ and materials absorption coefficient. In the open aperture, the materials absorption coefficient is leading to affecting the intensity. However, the magnitude of plane polarized laser beam diameter decreased towards the focal point and then same direction invert enlarged polarized laser beam will be get continuously. When the sample is moves in this region, the laser beam more interact with materials (absorption, refraction, transmission and 
reflection) and hence the transmitted remaining intensity is consider as a photocopy of materials property. The nonlinear refraction $\left(n_{2}\right)$ and nonlinear absorption $(\beta)$ of PTCZ crystal can be calculated by the closed and open aperture Z-scan curves respectively, which are shown in Fig. 18 (a) and (b). Here, the sample direction of the movement is very important. The pre-focal point region is $-\mathrm{z}$ as well as $+\mathrm{z}$ for the post-focal region in the translation stage. In this experiment, the closed aperture observed that the spectrum has valley to peak and hence crystal has self-focusing nature $\left(+n_{2}\right)$. The open aperture spectrum has valley at focal point $(\mathrm{z}=0)$, it represent the grown PTCZ single crystal has two/multi-photons absorption or reverse saturation absorption $(+\beta)$.

In order to find out the $n_{2}$, the $\Delta T_{p-v}$ has been obtained by the taken of difference in transmittance peak and valley in the closed aperture data. The nonlinear refractive index $\left(n_{2}\right)$ of the PTCZ crystal was calculated using the following relation:

$$
n_{2}=\frac{\Delta \phi}{k I_{0} L_{e f f}}\left(m^{2} / W\right)
$$

Where,

$$
\begin{aligned}
& |\Delta \varphi|=\frac{\Delta T_{p-v}}{0.406(1-S)^{0.25}} \\
& S=1-\exp \left(\frac{-2 r_{a}{ }^{2}}{\omega_{a}^{2}}\right)
\end{aligned}
$$

where $S$ is the linear transmittance through an aperture, $r_{a}$ is the radius of aperture and $\omega_{a}$ is the beam radius at the aperture. 
The nonlinear absorption co-efficient $(\beta)$ can be determined using an open aperture data and using the formula.

$$
\beta=\frac{2 \sqrt{2} \Delta T}{I_{0} L_{e f f}}(m / W)
$$

where $k$ is the $2 \pi / \lambda, \Delta T$ is obtained from open aperture spectrum and $I_{0}$ is intensity at the focal point $\left(27.25 \mathrm{MW} / \mathrm{m}^{2}\right)$. The value of $n_{2}$ is $3.221 \times 10^{-11} \mathrm{~m}^{2} / \mathrm{W}$ and $\beta$ is $1.274 \times 10^{-4} \mathrm{~m} / \mathrm{W}$. The third order nonlinear optical susceptibility $\left(\chi^{(3)}\right)$ were estimated using the following equations [10, 39].

$$
\chi^{(3)}=\sqrt{\left(R_{e} \chi^{(3)}\right)^{2}+\left(I_{m} \chi^{(3)}\right)^{2}}
$$

Where,

$$
\begin{aligned}
& R_{e} \chi^{(3)}(e s u)=\frac{10^{-4} \varepsilon_{0} c^{2} n_{0}{ }^{2} n_{2}}{\pi}\left(\mathrm{cm}^{2} / W\right) \\
& I_{m} \chi^{(3)}(e s u)=\frac{10^{-2} \varepsilon_{0} c^{2} n_{0}{ }^{2} \lambda \beta}{4 \pi^{2}}(\mathrm{~cm} / W)
\end{aligned}
$$

Resultant, the absolute value of third order nonlinear susceptibility $\left(\chi^{(3)}\right)$ was found to be $7.068 \times 10^{-8}$ esu. The $\chi^{(3)}$ value of PTCZ single crystal has higher than the other standard materials [40-43] and the comparison details are given in the Table. 4. The materials possess positive sign of the $n_{2}$ and it indicates that the self-focusing nature. This is the advantage for optical limiting and frequency conversion applications [44].

\section{Conclusions}

The good quality piperazinium tetrachlorozincate monohydrate (PTCZ) single crystal were grown by solvent evaporation method. The crystal structure and its morphology were analyzed single crystal X-ray diffraction (XRD) supported with WinXMorph software. The functional 
groups of the present systems were identified. The crystal has good optical transmittance in entire visible and UV region and also lower cut-off was found to be around $180 \mathrm{~nm}$. The optical band gap energy was found to be $6.2 \mathrm{eV}$. The thermal stability of PTCZ is $70{ }^{\circ} \mathrm{C}$ and also PTCZ is belongs to the mechanically soft material category. The grown PTCZ single crystal has higher third order nonlinear susceptibility $\left(\chi^{(3)}\right)$, which is most suitable for frequency conversion applications.

\section{Acknowledgment}

The authors are thankful to SAIF, IIT-Madras for single crystal XRD analysis. We thank NCIF, National College, Tiruchirappalli for hardness studies measurement.

\section{References}

[1] P. E. Britton, N. G. R. Broderick, D. J. Richardson, P. G. R. Smith, G. W. Ross, and D. C. Hanna, Optics Letters Vol. 23, Issue 20, pp. 1588-1590 (1998).

[2] Duanliang Wang, Tingbin Li, Shenglai Wang, Jiyang Wang, Zhengping Wang, Xinguang Xu, and Fang Zhang, RSC Adv., 2016,6, 14490-14495.

[3] Tanusri Pal, Tanusree Kar, Gabriele Bocelli, and Lara Rigi, Crystal Growth \& Design, 2003, 3 (1), pp 13-16.

[4] N. Prabavathi, A. Nilufer, V. Krishnakumar, Spectrochim. Acta A 121 (2014) 483-493.

[5] A. Parkin, I.D.H. Oswald, S. Parsons, ActaCrystallogr, Sect. B: Struct. Sci, 60 (2004) 219227.

[6] S. Ranga Reddy, P. Manikyamba, J. Chem. Sci, 119 (2007) 613-616.

[7] Tran Qui, D.; Palacios, E.. Acta Ciystallogr. C46 (1990) 1212-1215.

[8] Ishihara, H.; Horiuchi, K.; Gesing, T. M.; Dou, S.; Buhl, I. C.; Eric, P. Z. Naturforsch. B57 (2002) 503-508. 
[9] R. Kefi and C. Ben Nasr, Z. Kristallogr. NCS 220 (2005) 241-242.

[10] P. Karuppasamy, M. Senthil Pandian, P. Ramasamy, Journal of Crystal Growth, 473 (2017) $39-54$.

[11] P. Rekha, G. Peramaiyan, M. Nizam Mohideen, R. Mohan Kumar, R. Kanagadurai, Spectrochim. Acta Mol. Biomol. Spectrosc. 139 (2015) 302-306.

[12] S. Gunasekaran, B. Anita, Indian Journal of Pure and Applied Physics 46(2008) 833-838.

[13] V. Pandey, N. Mehta, S.K. Tripathi, A. Kumar, Chalcogenide Letters 2 (2005) 2641-2646.

[14] R.E. Denton, R.D. Campbell, S.G. Tomlin, Journal of Applied Physics 5 (1972) 852-863.

[15] Mott, NF, Davis, EA: Electron processes in non-crystalline materials. Clarendon, Oxford (1979).

[16] Tauc, J, Menth, A: States in the gap. J Non-Cryst Solids 569, 8-10 (1972)

[17] Sahebi Ramezan, J. Mater. Sci. Mater. Electron 31 (2020) 12041-12043.

[18] Sahebi Ramezan, Chin. J. Phys 66 (2020) 109-111.

[19] A.S. Gill, S. Kalainathan, Mater. Lett. 65, 53-55 (2011).

[20] K. Sangwal, Mater. Chem. Phys. 63 (2000) 145-152.

[21] E. Meyer, Z. Ver. Dtsch. Ing. 52 (1908) 645-654.

[22] S. Karan, S.P.S. Gupta, Mater. Sci. Eng. A 398, 198-203 (2005)

[23] B.R. Lawn, D.B. Marshall, J. Am. Ceram. Soc. 62 (1979) 347

[24] H. Ishikaa, N. Skinkai, J. Am. Ceram. Soc. 65 (1980) C124-C127

[25] K. Nihara, R. Morena, D.P.H. Hasselman, J. Mater. Sci. Lett. 1 (1982) 13

[26] W.A. Wooster, Rep prog phys 16 (1953) 62-82

[27] P. Karuppasamy, M. Senthil Pandian, P. Ramasamy, Sunil Verma, Optical Materials, 79 (2018) 152-171. 
[28] P.V. Rysselberghe, J. Phys. Chem. 36 (1932) 1152-1155.

[29] N.M. Ravindra, V.K. Srivastava, J. Infrared Phys. 20 (1980) 67-69.

[30] D. R. Penn, Phys. Rev 128 (1962) 2093-2097

[31] C. Balarew, R. Duhlew, J. Solid State Chem 55 (1984) 1-6.

[32] M. Born, E. Wolf. Osnovy optiki, second ed., Moscow, 1973

[33] A. Dev, S. Chakrabarti, S. Kar, S. Chaudhuri, J. Nanopart. Res. 7 (2005) 195-201.

[34] B.R. Lawn, D.B. Marshall, J. Am. Ceram. Soc. 62 (1979) 347-350

[35] S.K. Sharma, Sunil Verma, Yeshpal Singh, K.S. Bartwal, M.K. Tiwari, G.S. Lodha, G. Bhagavannarayana, Optical Materials, 46 (2015) 329-338.

[36] G. Bhagavannarayana, S. Parthiban and S. Meenakshisundaram, Cryst. Growth Des., 2008, 8,446 .

[37] M. Sheik - Bahae, A. A. Said, T. H. Wei, D. J. Hagan E. W. Van Stryland, IEEE J. Quantum Electron 26 (1990) 760 - 769.

[38] P. Karuppasamy, V. Sivasubramani, M. Senthil Pandian and P. Ramasamy, RSC Adv. 6 (2016) 109105-109123.

[39] E. W. Van Stryland, M. Sheik-Bahae, M.G. Kuzyk and C. W. Dirk, Eds. New York: Marcel Dekker, (1998) 655-692.

[40] D. Wang, T. Li, S. Wang, J. Wang, Z. Wang, X. Xu, F. Zhang, RSC Adv 6 (2016) 1449014495.

[41] M. Sukumar, R. Ramesh Babu, K. Ramamurthi, Appl. Phys. B 121 (2015) 369-373.

[42] M. Yin, H.P. Li, S.H. Tang, W. Ji, Appl. Phys. B 70 (2000) 587-591.

[43] F.Q. Li, N. Zong, F.F. Zhang, J. Yang, F. Yang, Q.J. Peng, D.F. Cui, J.Y. Zhang, X.Y. Wang, C.T. Chen, Z.Y. Xu, Appl. Phys. B 108 (2012) 301-305. 
[44] D. Wolfersberger, N. Fressengeas, J. Maufoy, G. Kugel, J. Nonlinear Opt. Phys. Mater. 9 (2000) 441-450. 
Figures

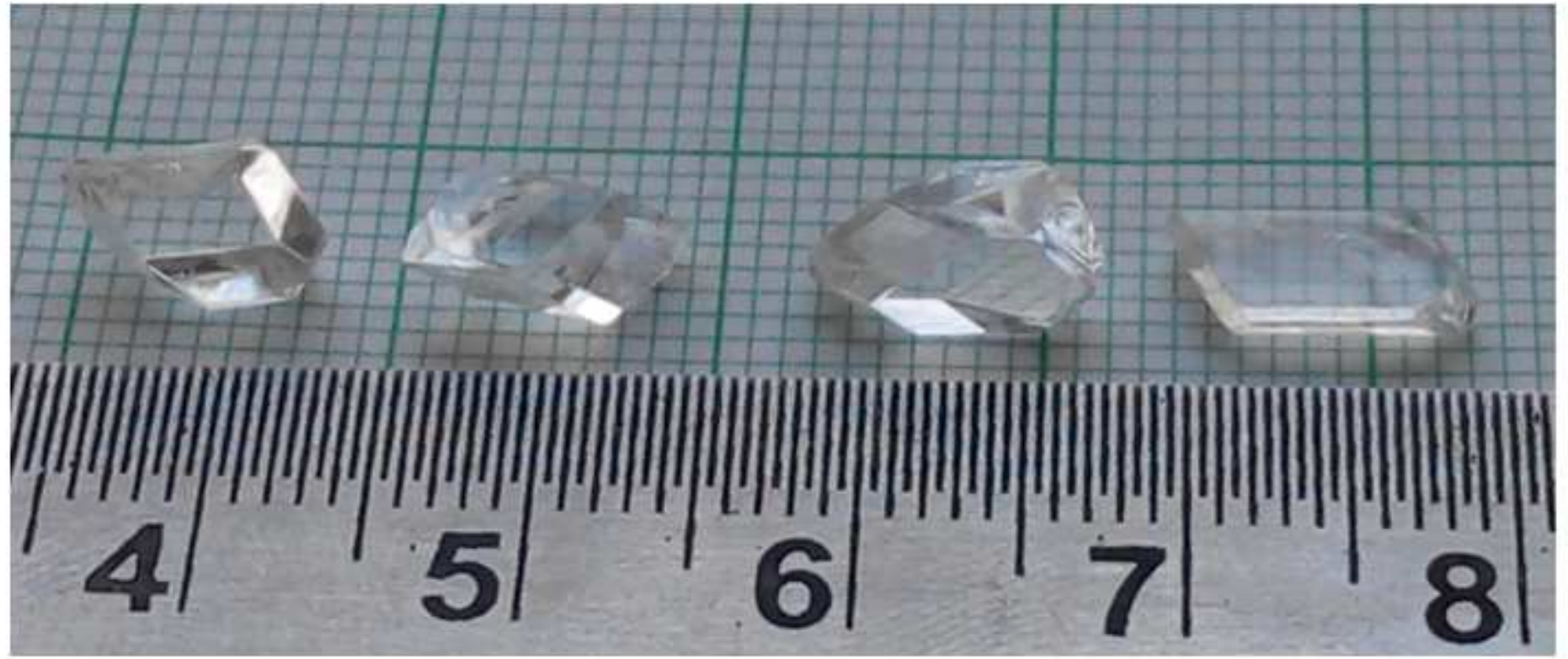

Figure 1

As grown crystals of PTCZ

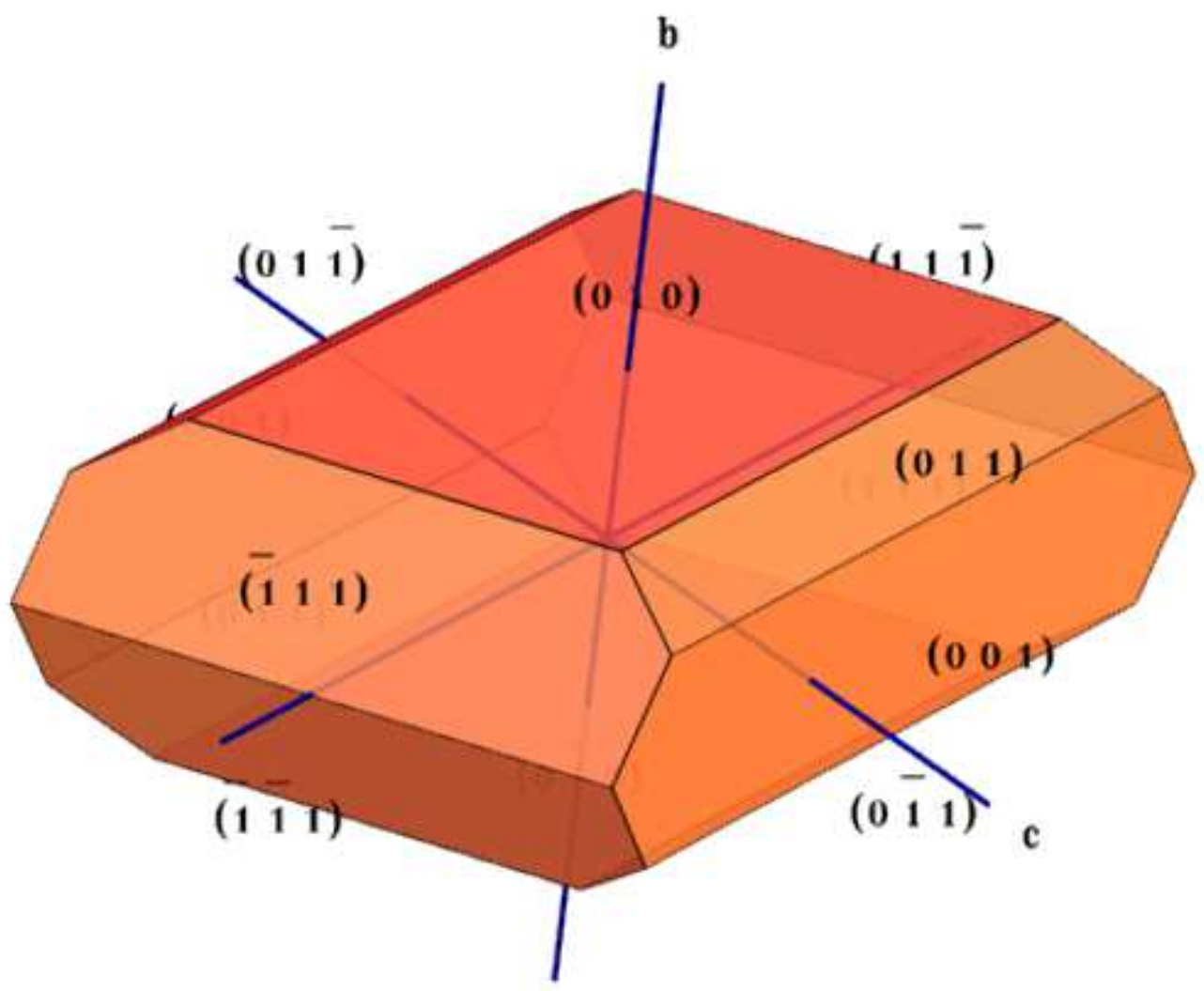


Figure 2

Morphology of PTCZ

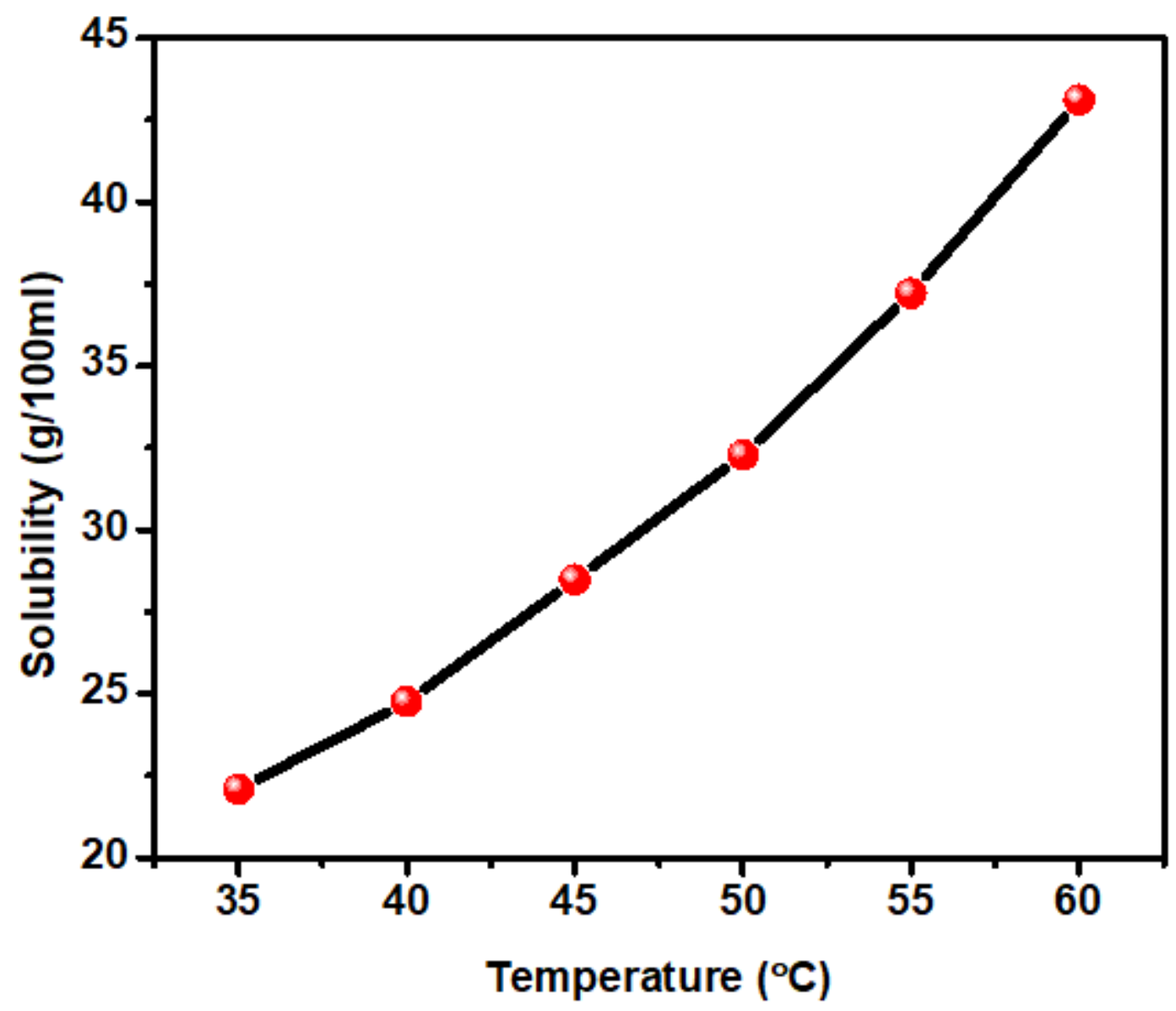

Figure 3

Solubility curve of grown PTCZ 


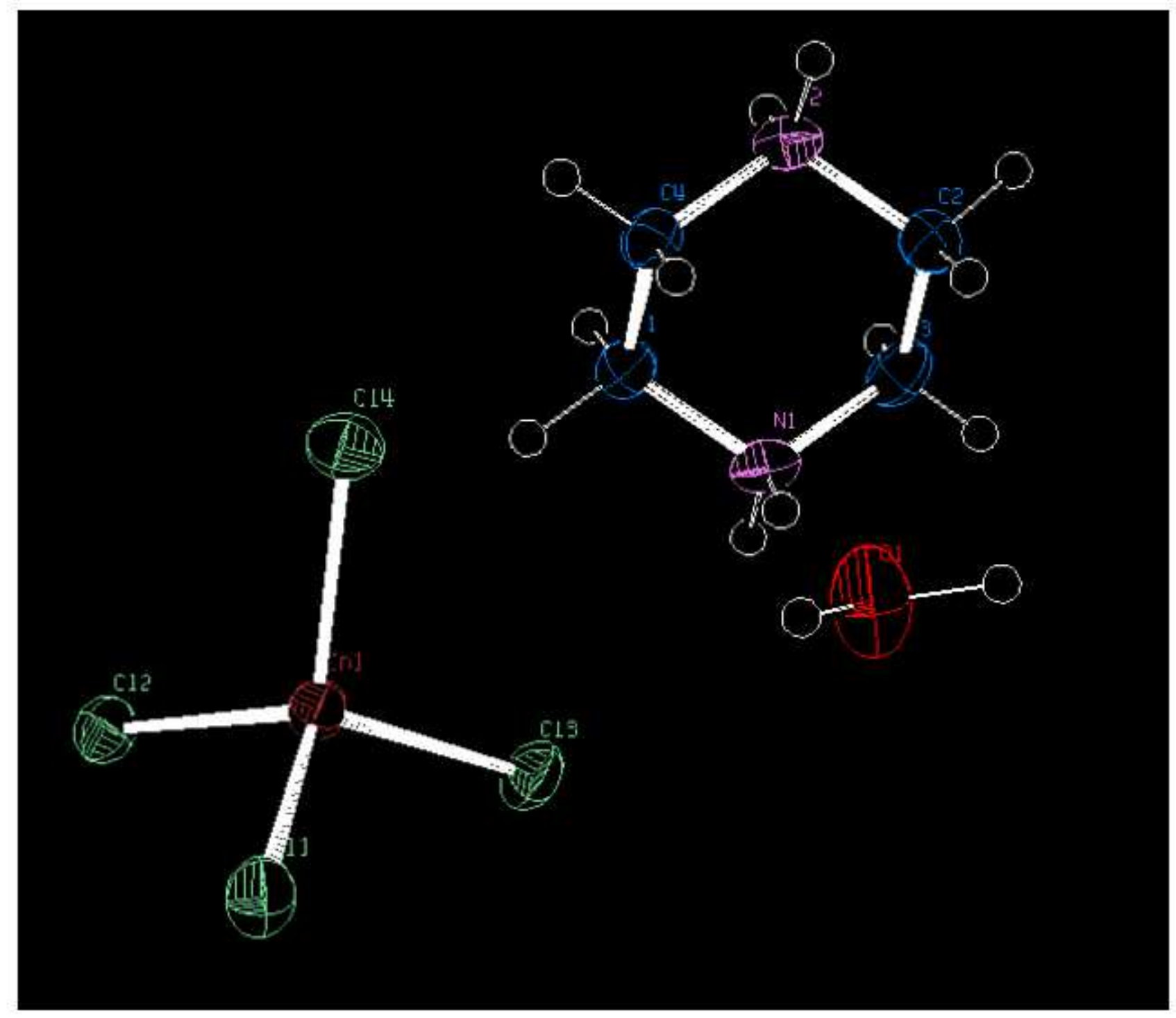

Figure 4

ORTEP diagram of PTCZ molecule 


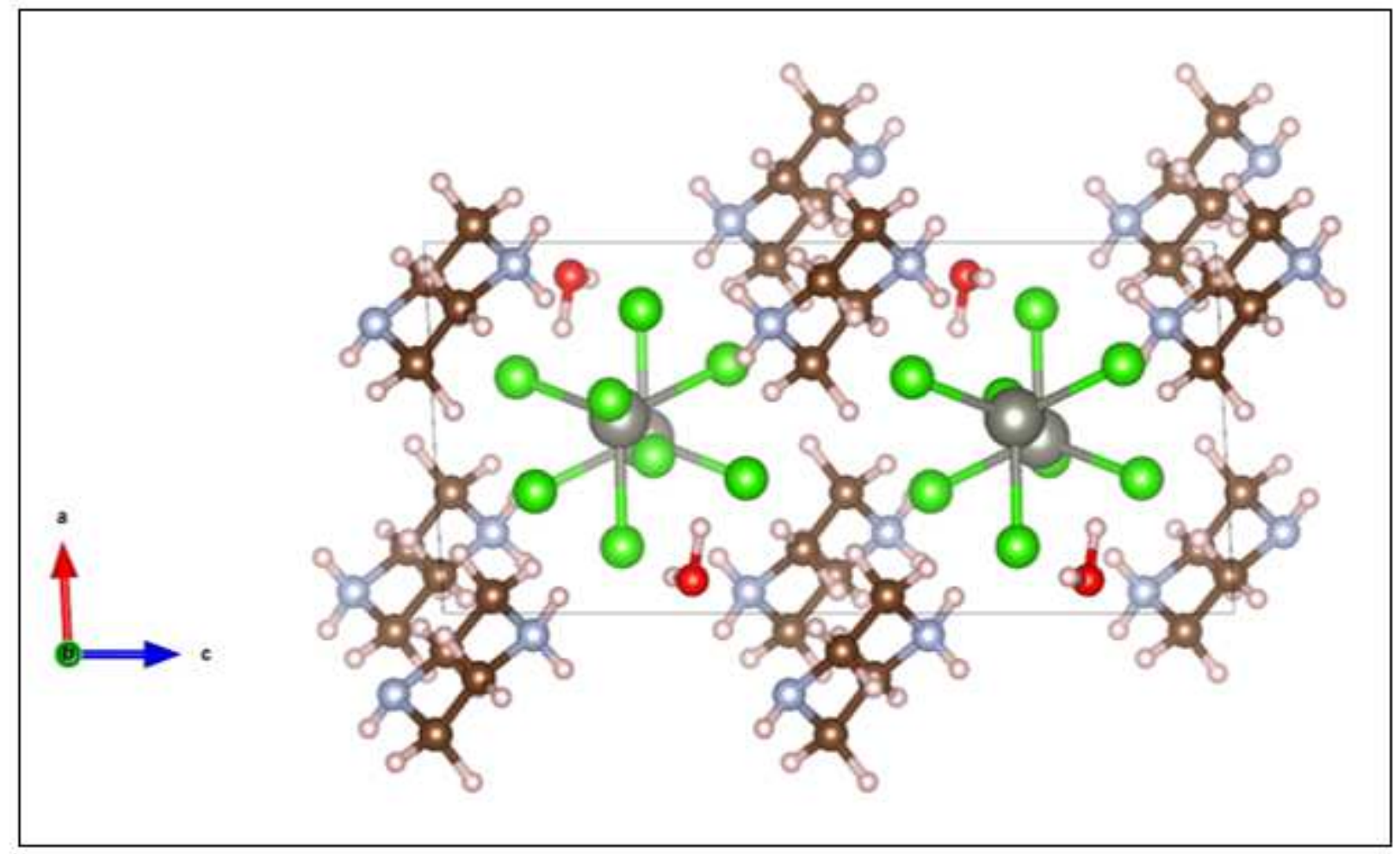

Figure 5

Packing diagram of PTCZ 


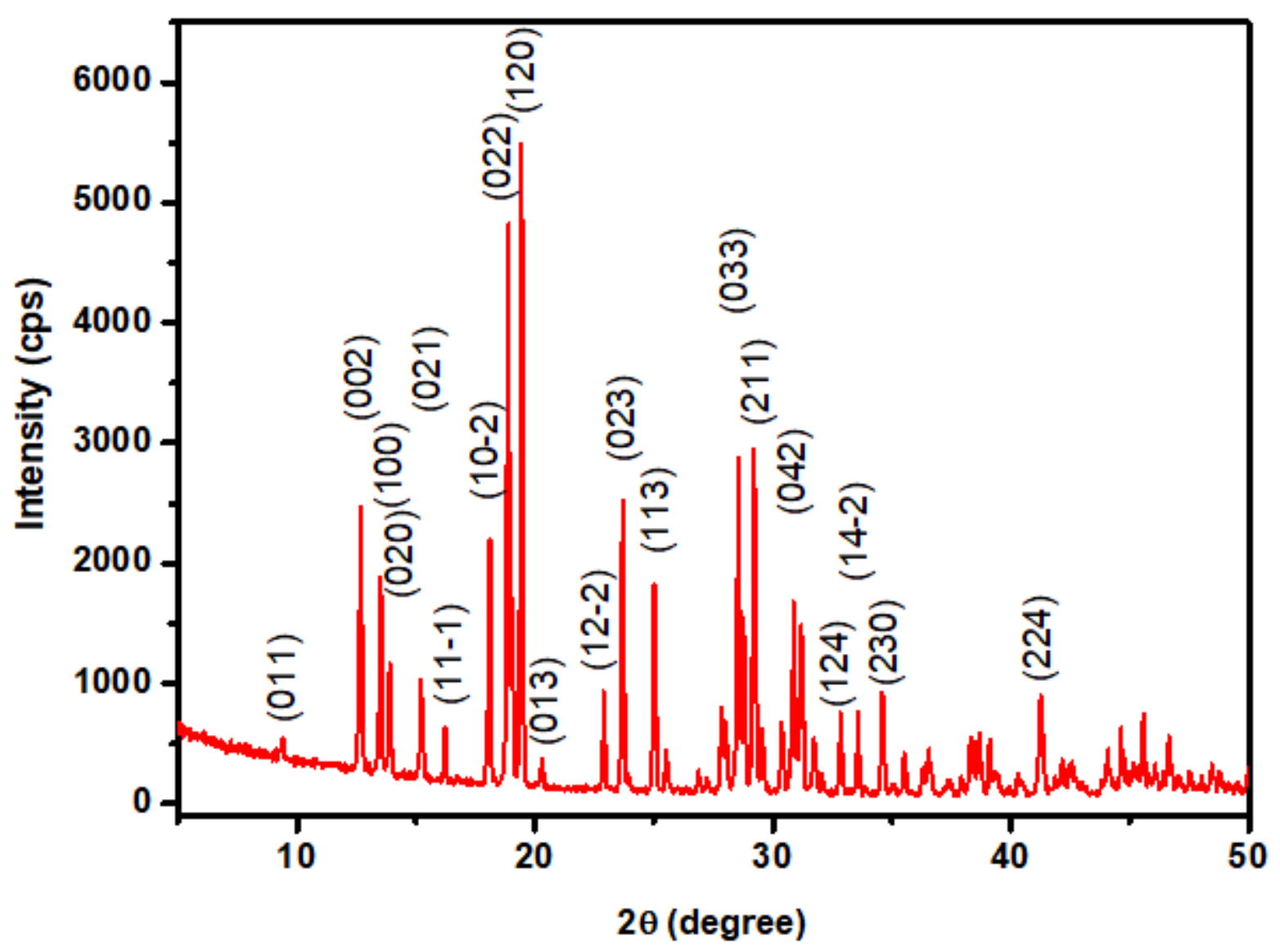

Figure 6

PXRD of PTCZ 


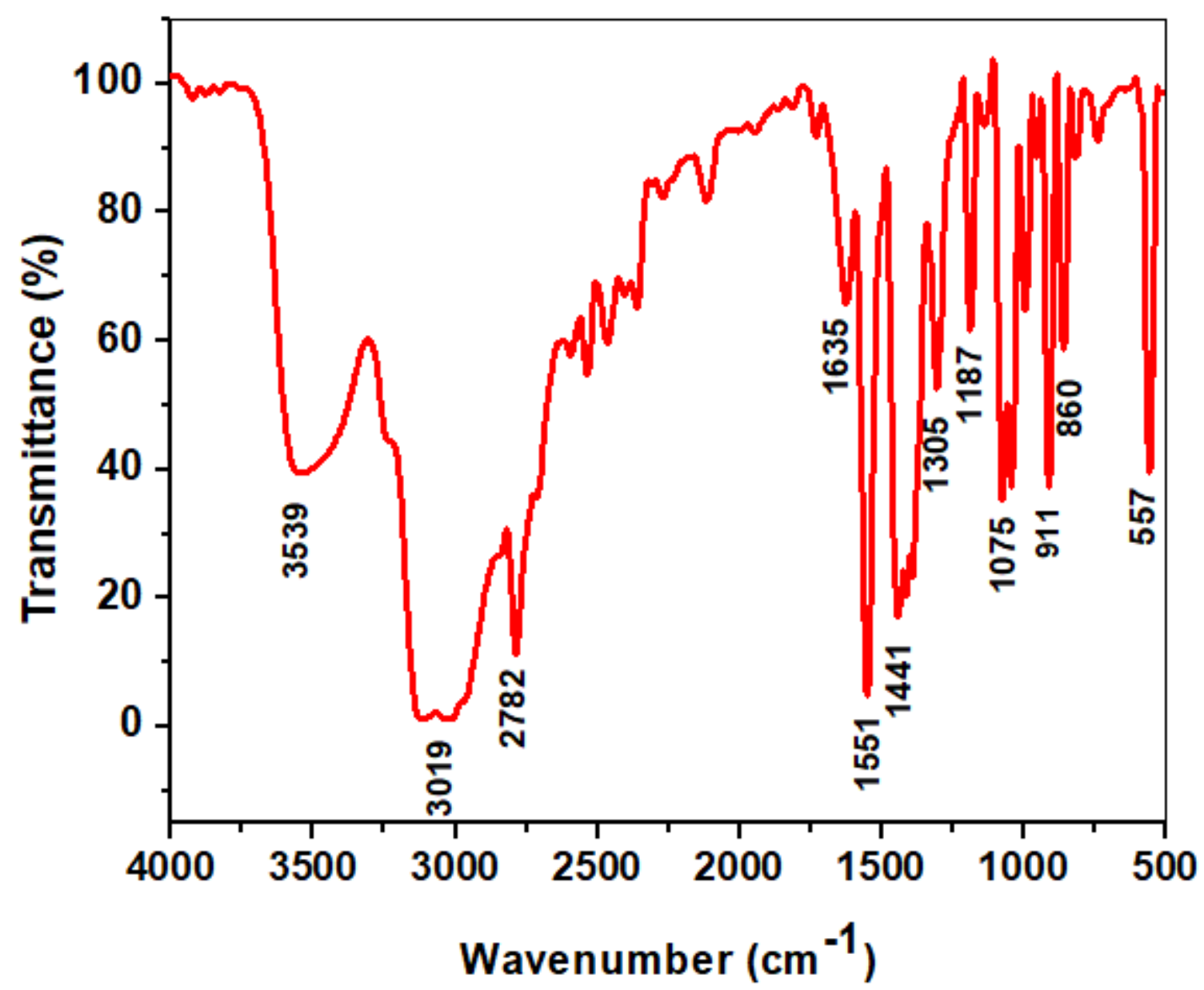

Figure 7

FTIR spectrum of PTCZ
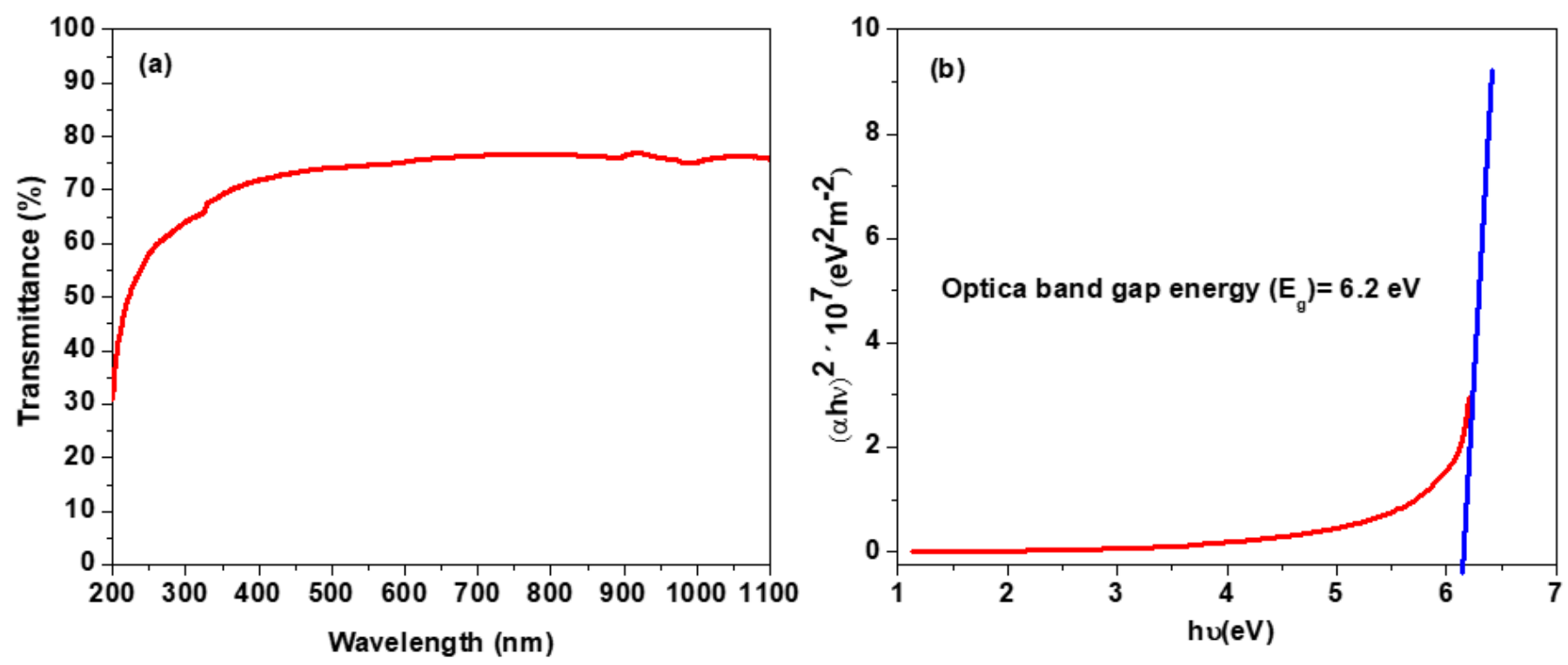
Figure 8

(a) Optical transmittance spectrum of PTCZ and (b) Band gap energy of PTCZ
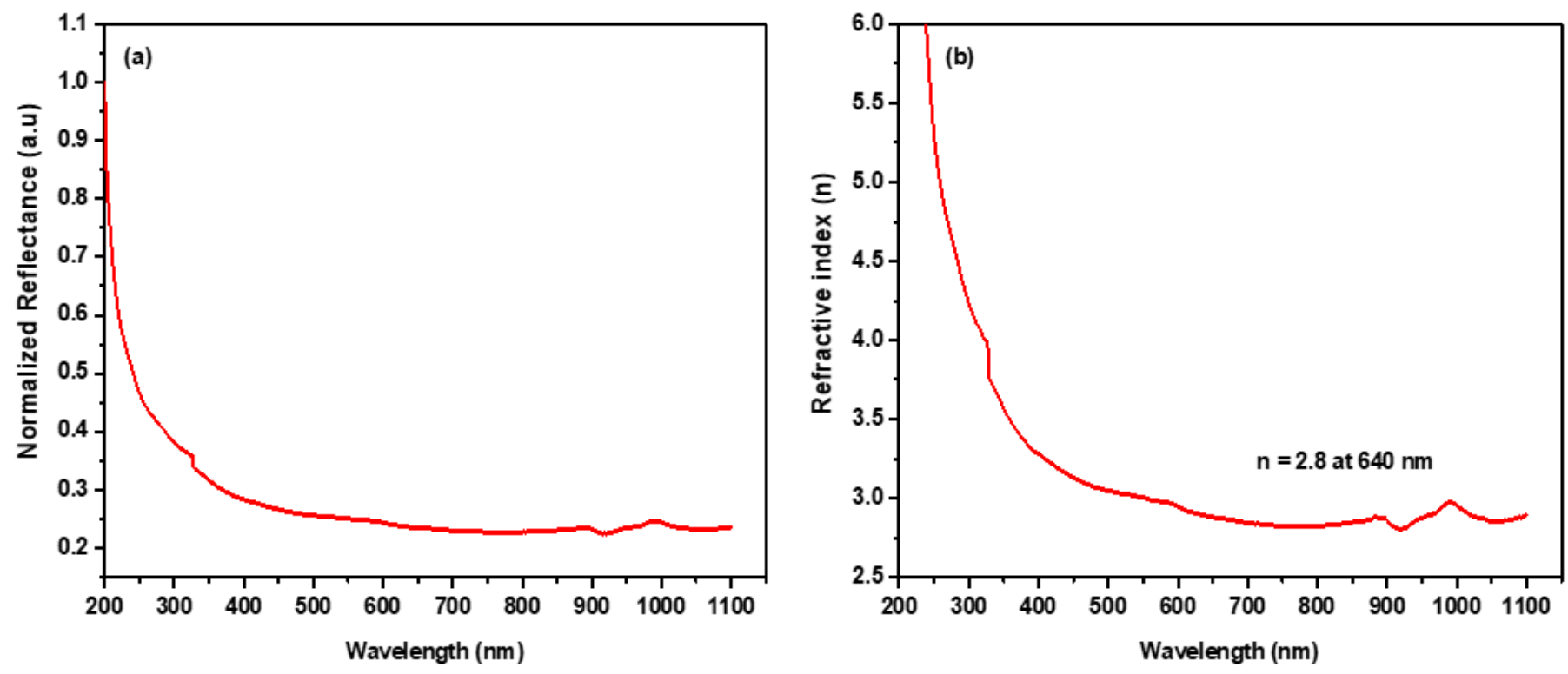

Figure 9

(a) Reflectance and (b) Refractive index versus wavelength 


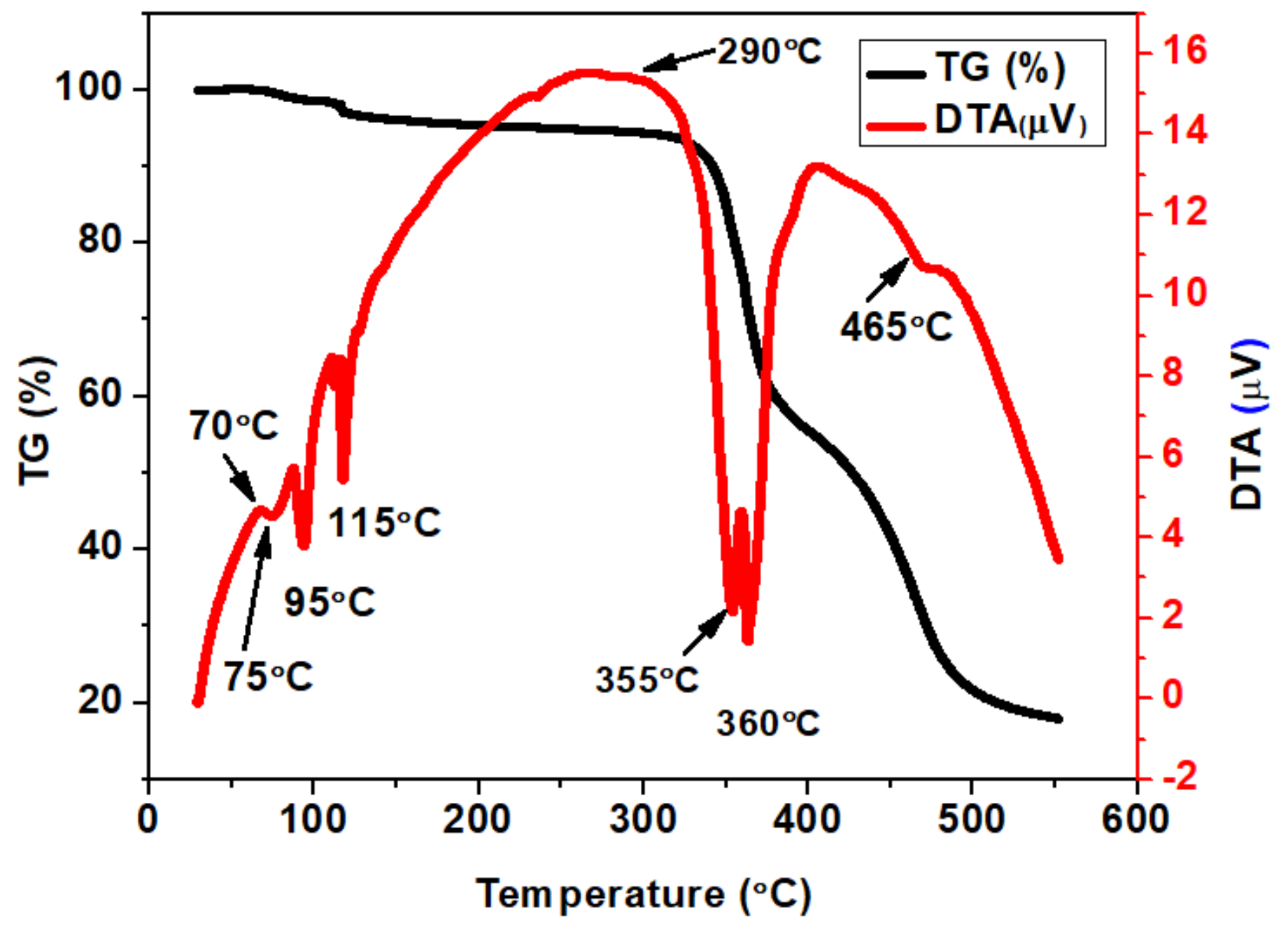

Figure 10

Thermal analysis of grown crystal 

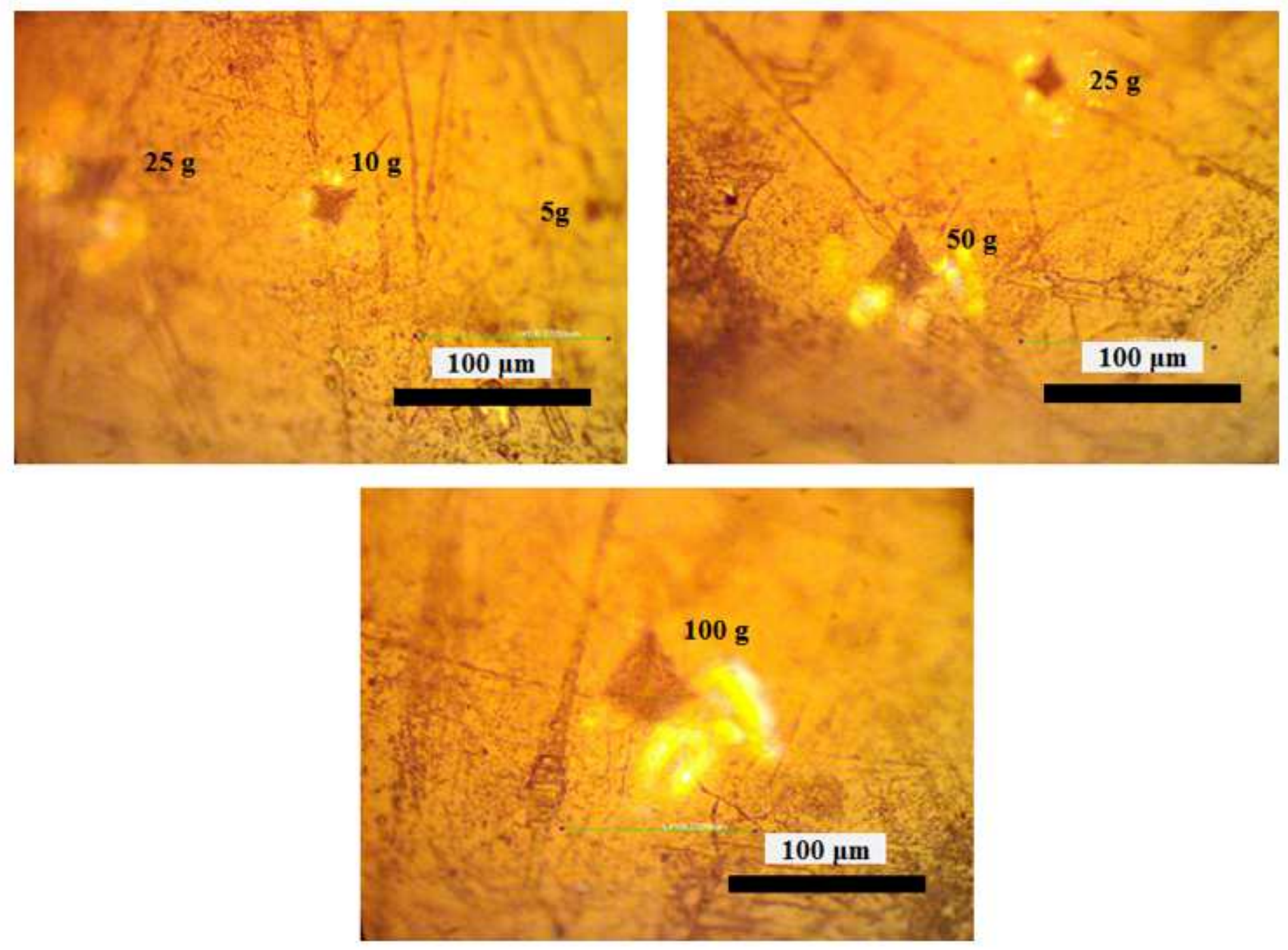

\section{Figure 11}

Indentation patterns of PTCZ single crystal 

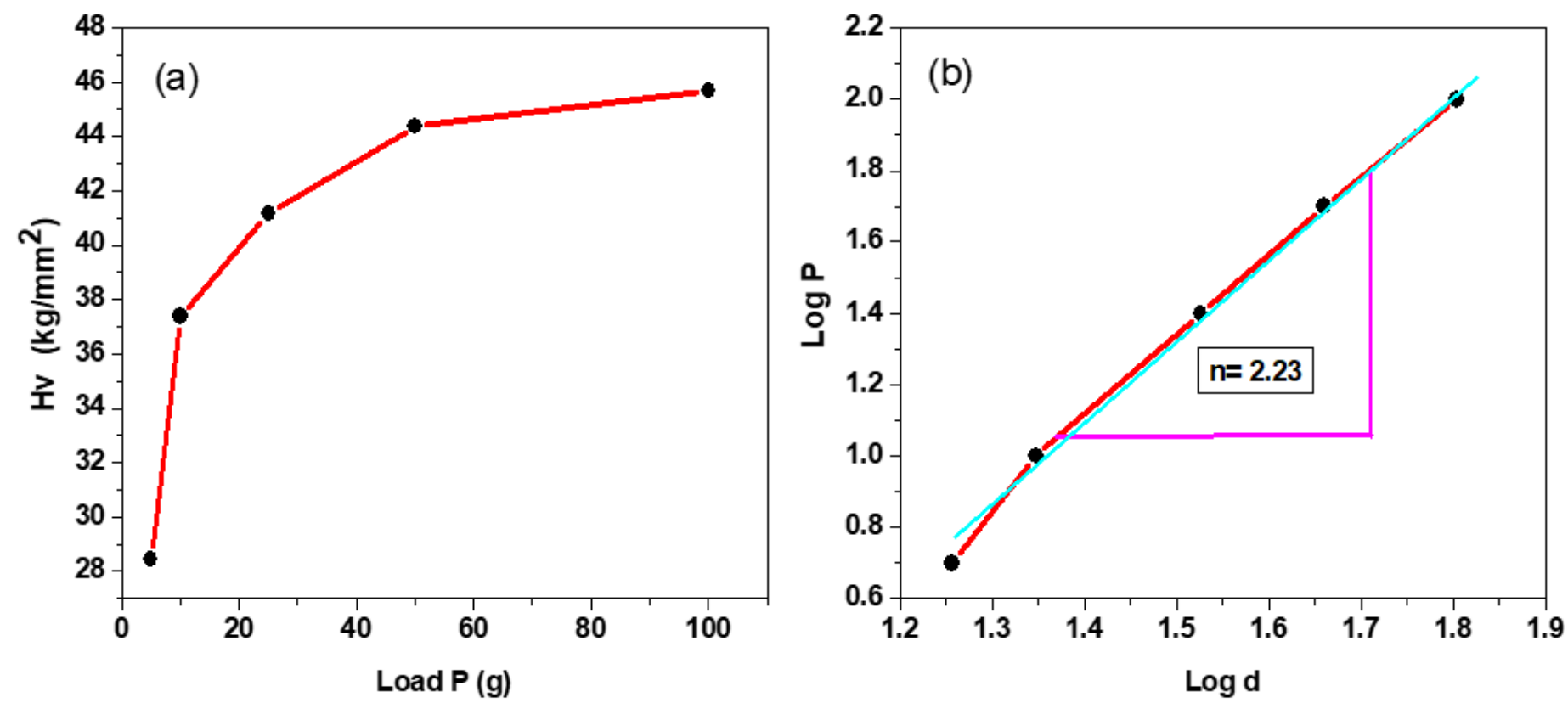

Figure 12

(a) Hv versus $\mathrm{P}$ and (b) Log $\mathrm{P}$ versus Log d 

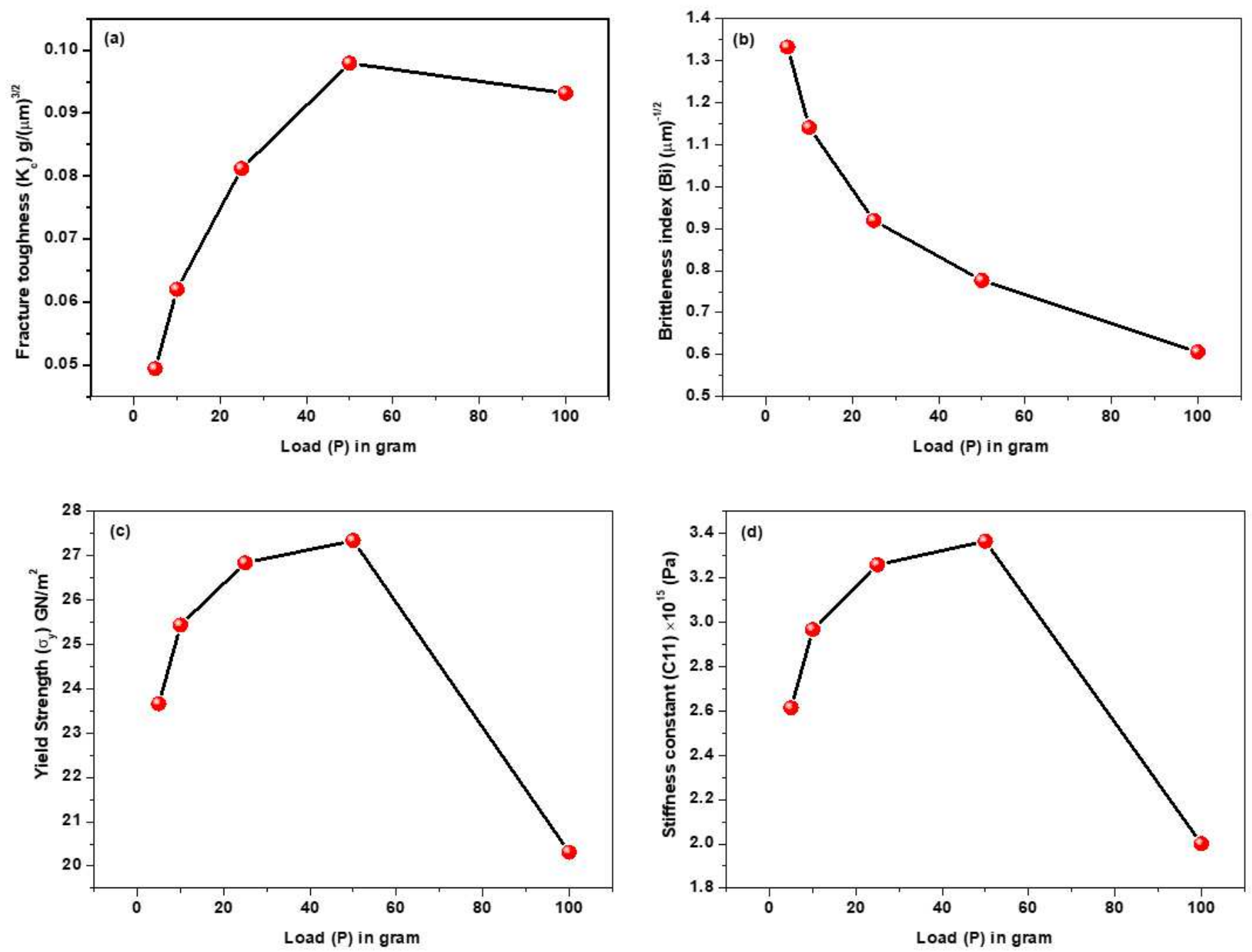

Figure 13

(a) fracture toughness $(\mathrm{Kc})$, brittleness index (Bi), yield strength ( $\sigma \mathrm{y})$ and elastic stiffness constant (C11) 

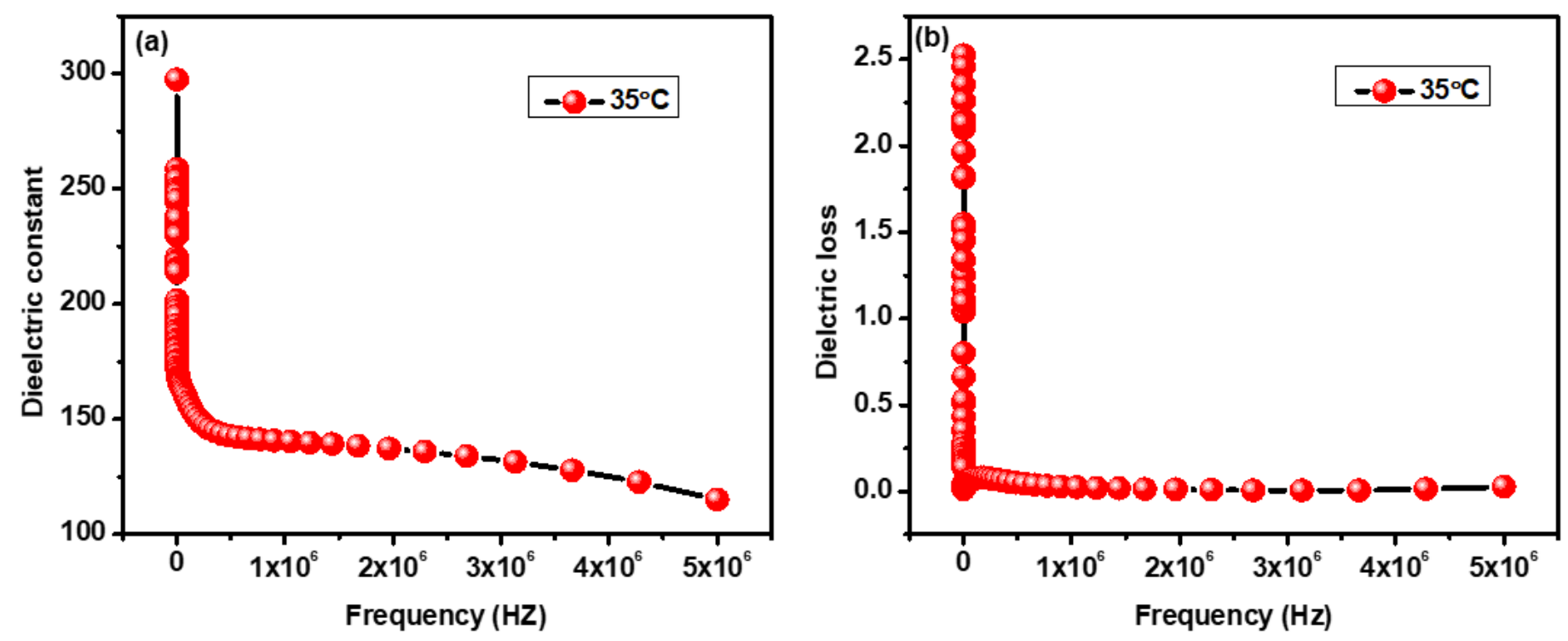

Figure 14

(a) Dielectric constant and (b) dielectric loss
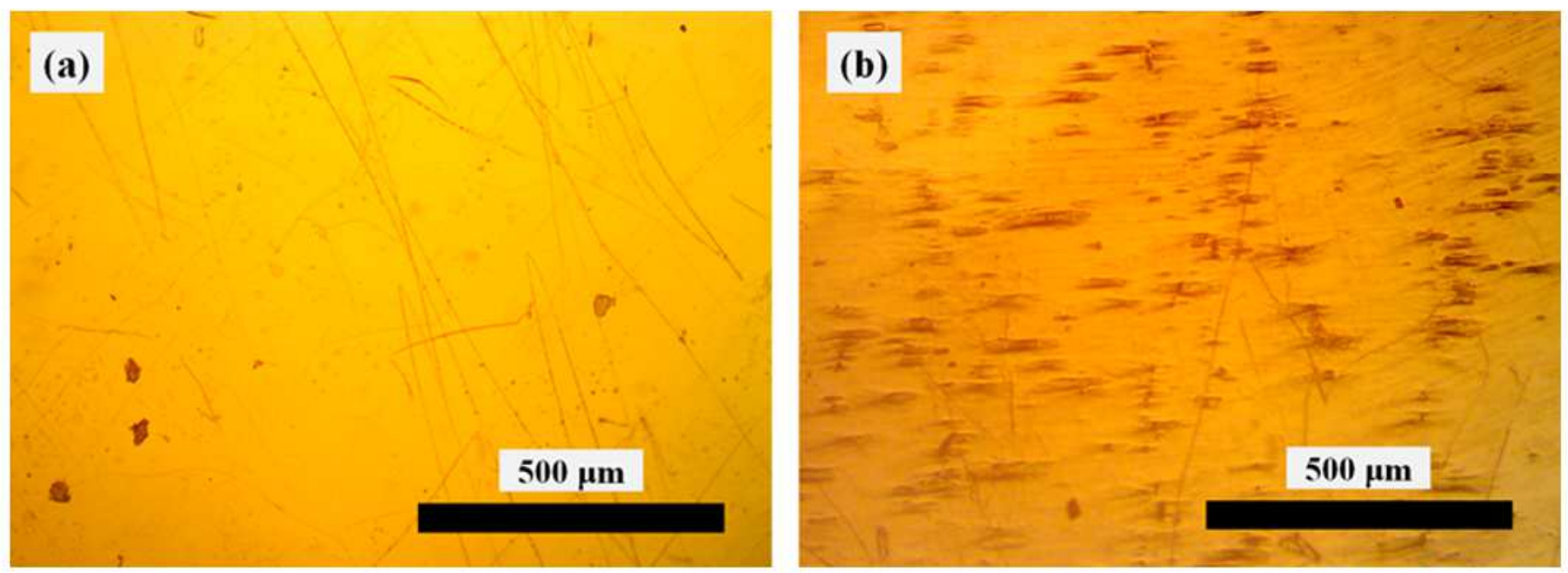

Figure 15

(a) As grown and (b) etched surfaced for 5 sec of PTCZ single crystal 


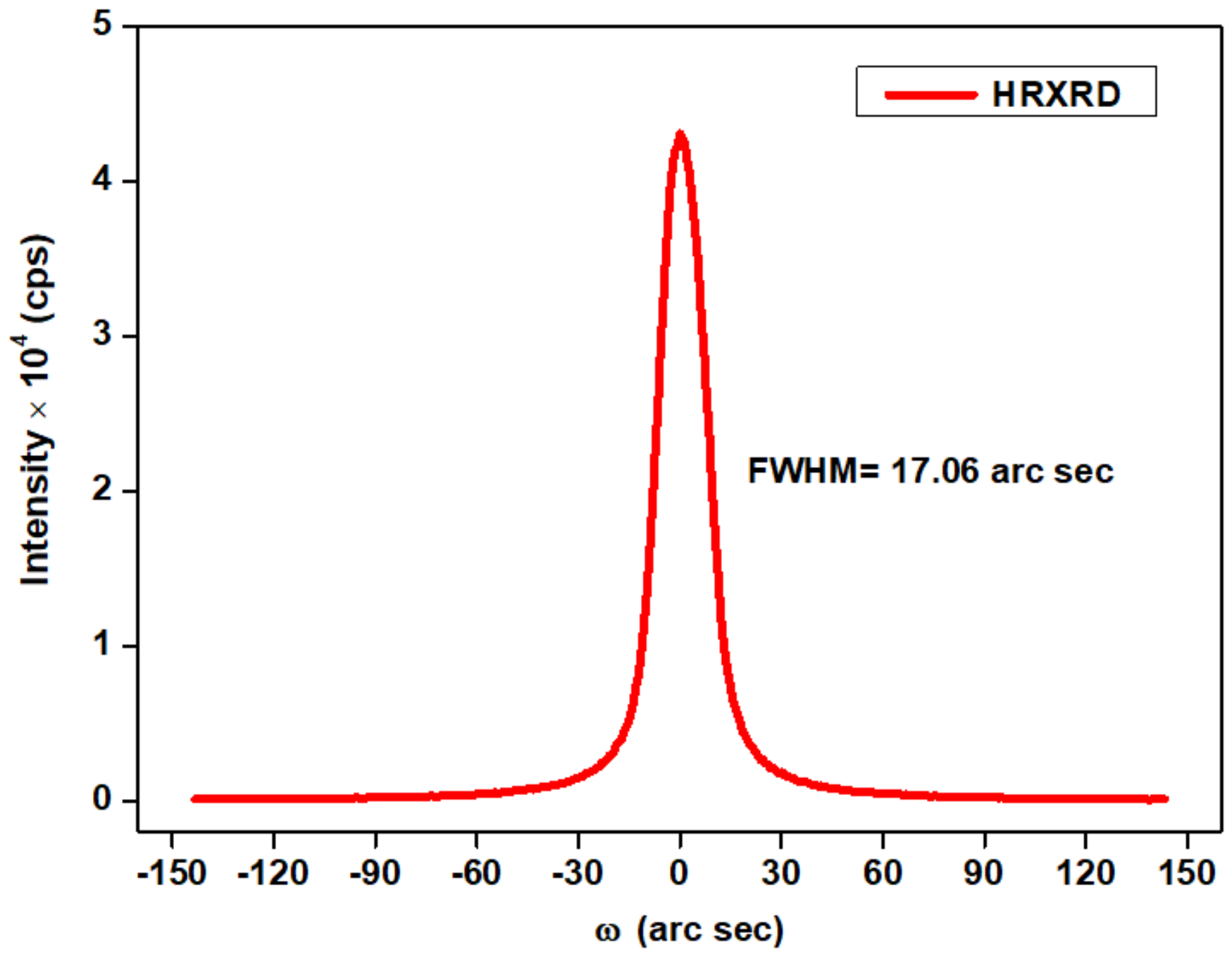

Figure 16

Rocking curve (RC) of the PTCZ single crystal

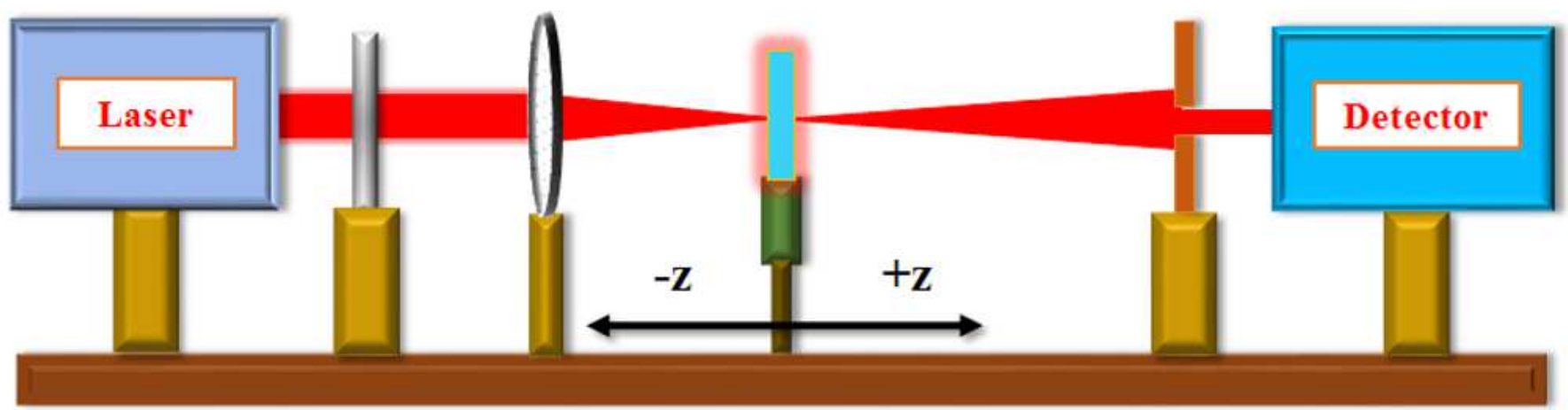

Figure 17 
Schematic diagram of Z-scan system
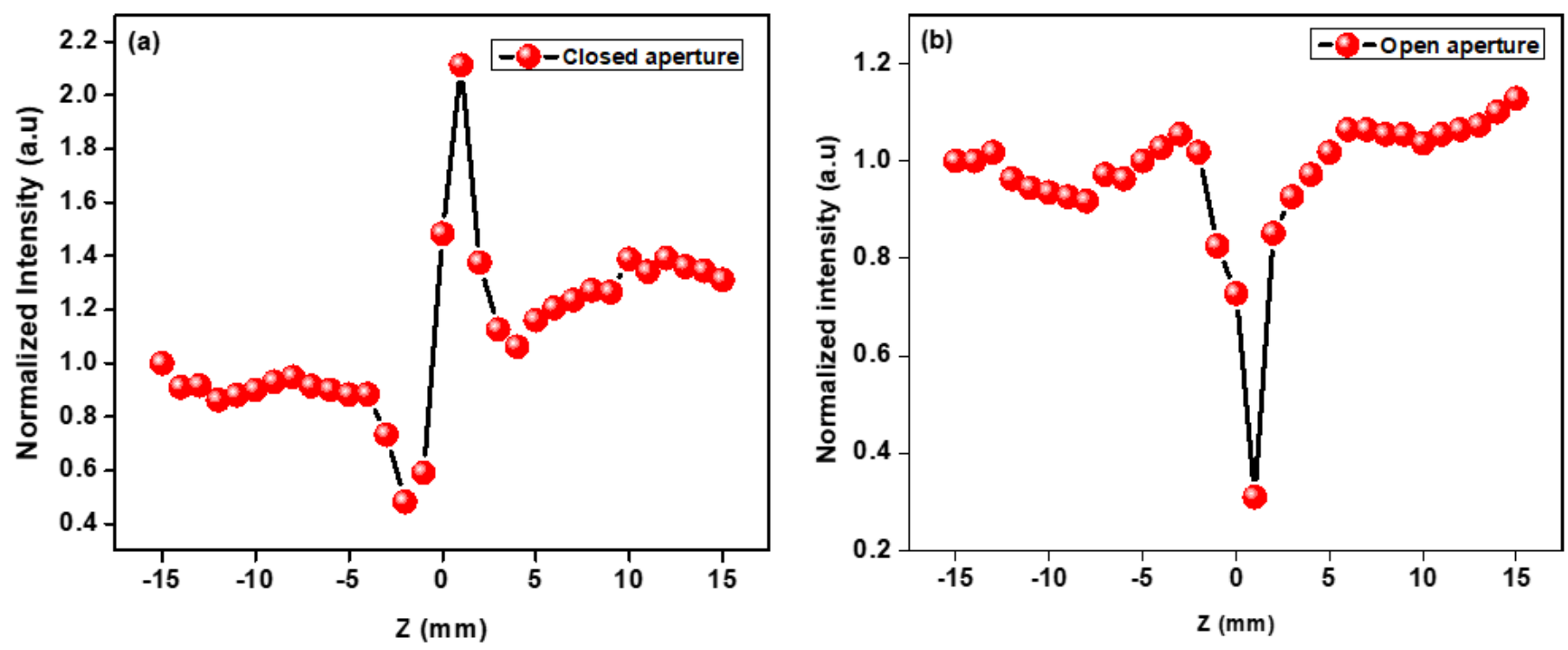

Figure 18

Z-scan spectra of (a) Closed aperture spectrum and (b) Open aperture spectrum

\section{Supplementary Files}

This is a list of supplementary files associated with this preprint. Click to download.

- Tablecaption.docx 